\title{
Surface vacuolar ATPase in ameloblastoma contributes to tumor invasion of the jaw bone
}

\author{
SHOHEI YOSHIMOTO ${ }^{1,2 *}$, HIROMITSU MORITA ${ }^{3 *}$, RYOTA MATSUBARA $^{4}$, \\ TAKESHI MITSUYASU ${ }^{4}$, YUKO IMAI ${ }^{2}$, SHUNICHI KAJIOKA $^{5}$, MASAHIRO YONEDA $^{3}$, \\ YUSHI ITO $^{6}$, TAKAO HIROFUJI ${ }^{3}$, SEIJI NAKAMURA ${ }^{4}$ and MASATO HIRATA ${ }^{1}$
}

\footnotetext{
${ }^{1}$ Laboratory of Molecular and Cellular Biochemistry, Faculty of Dental Science, Kyushu University, Fukuoka 812-8582;

${ }^{2}$ Special Patient Oral Care Unit, Kyushu University Hospital, Fukuoka 812-8582; ${ }^{3}$ Department of General Dentistry, Fukuoka Dental College, Fukuoka 814-0193; ${ }^{4}$ Section of Oral and Maxillofacial Oncology, Division of Maxillofacial

Diagnostic and Surgical Sciences, Faculty of Dental Science, Kyushu University, Fukuoka 812-8582;

${ }^{5}$ Department of Urology, Graduate School of Medical Sciences, Kyushu University, Fukuoka 812-8582;

${ }^{6}$ Department of Physiology, School of Medicine, Kurume University, Kurume 830-0011, Japan
}

Received October 26, 2015; Accepted December 29, 2015

DOI: $10.3892 /$ ijo.2016.3350

\begin{abstract}
Ameloblastoma is the most common benign odontogenic tumor in Japan. It is believed that it expands in the jaw bone through peritumoral activation of osteoclasts by receptor activator of nuclear factor kappa-B ligand (RANKL) released from the ameloblastoma, as in bone metastases of cancer cells. However, the clinical features of ameloblastoma, including its growth rate and patterns of invasion, are quite different from those of bone metastasis of cancer cells, suggesting that different underlying mechanisms are involved. Therefore, in the present study, we examined the possible mechanisms underlying the invasive expansion of ameloblastoma in the jaw bone. Expression levels of RANKL assessed by western blotting were markedly lower in ameloblastoma (AM-1) cells than in highly metastatic oral squamous cell carcinoma (HSC-3) cells. Experiments coculturing mouse macrophages (RAW264.7) with AM-1 demonstrated low osteoclastogenic activity, as assessed by tartrate-resistant acid phosphatase (TRAP)-positive multinuclear cell formation, probably because of low release of RANKL, whereas
\end{abstract}

Correspondence to: Dr Hiromitsu Morita, Department of General Dentistry, Fukuoka Dental College, 2-15-1 Tamura, Sawara-ku, Fukuoka 814-0193, Japan

E-mail:morita@college.fdcnet.ac.jp

Dr Masato Hirata, Laboratory of Molecular and Cellular Biochemistry, Faculty of Dental Science, Kyushu University, 3-1-1 Maidashi, Higashi-ku, Fukuoka 812-8582, Japan

E-mail: hirata1@dent.kyushu-u.ac.jp

*Contributed equally

Key words: ameloblastoma, RANKL, demineralization, vacuolar ATPase, CLC-7 cocultures of RAW264.7 with HSC-3 cells exhibited very high osteoclastogenic activity. Thus, RANKL release from AM-1 appeared to be too low to generate osteoclasts. However, AM-1 cultured directly on calcium phosphate-coated plates formed resorption pits, and this was inhibited by application of bafilomycin A1. Furthermore, vacuolar-type $\mathrm{H}^{+}$-ATPase (V-ATPase) and $\mathrm{H}^{+} / \mathrm{Cl}^{-}$exchange transporter 7 (CLC-7) were detected on the surface of AM-1 cells by plasma membrane biotinylation and immunofluorescence analysis. Immunohistochemical analysis of clinical samples of ameloblastoma also showed plasma membrane-localized V-ATPase and CLC-7 in the epithelium of plexiform, follicular and basal cell types. The demineralization activity of AM-1 was only $1.7 \%$ of osteoclasts demineralization activity, and the growth rate was $20 \%$ of human normal skin keratinocytes and HSC-3 cells. These results suggest that the slow expansion of several typical types of ameloblastomas in jaw bone is attributable to its slow growth and low demineralization ability.

\section{Introduction}

Ameloblastoma is a common benign odontogenic tumor worldwide and is characterized by slow but steady invasion into the maxillary and mandibular bones. A histopathological classification of ameloblastoma by the World Health Organization in 2005 defined four types: solid/multicystic, extraosseous/ peripheral, desmoplastic and unicystic. Solid/multicystic ameloblastoma is further divided into follicular and plexiform types, including the basal cell type $(1,2)$. Although ameloblastoma is not a malignant lesion, treatment of any type of ameloblastoma is limited to surgical treatments such as enucleation and resection, although recurrence with significant morbidity is common after enucleation, particularly in young people (1-4). Accordingly, resection remains the best way to remove ameloblastoma, although this method is not without its drawbacks. Therefore, a better understanding of the pathophysiology of ameloblastoma is necessary, because there is a 
high demand for drugs capable of acting as selective inhibitors of ameloblastoma.

Expansion of solid/multicystic ameloblastoma in bone is thought to occur as a result of accelerated bone resorption activities by peritumoral osteoclasts. The activation of osteoclasts is triggered by the binding of receptor activator of nuclear factor kappa-B ligand (RANKL), which is released from vicinal ameloblastoma cells, to bind receptor activator of nuclear factor kappa-B (RANK) on the plasma membrane of osteoclasts, in a manner similar to that seen in boneinvasive cancers, particularly oral squamous cell carcinoma (SCC) (5-8). Furthermore, several matrix metalloproteinases (MMP; MMP-1, MMP-2 and MMP-9) released from ameloblastoma cells are also involved in progression of invasive lesions similar to that seen in oral invasive SCC (9-15). However, ameloblastoma exhibits clinical features that differ from those of oral SCC, including its bone invasion patterns, rate of spread and clinical symptoms. For example, solid/multicystic ameloblastoma and bone invasion of SCC show clear differences on X-ray transmission images $(1,16,17)$. The border of a solid/multicystic ameloblastoma of the jaw bone is well defined, smooth and scalloped, and the stroma exhibits a characteristic soap bubble or honeycomb appearance, often accompanied by knife-edge-like dental root resorption. In contrast, the borders of other bone invasive cancers are less well defined, often showing marked bone resorption similar to that seen in severe periodontitis, and are characterized by floating teeth without root resorption $(1,16,17)$. These differences are likely caused by the extremely slow spread of ameloblastoma relative to that of bone-invading cancer cells derived from oral tissues, breast, lung and other organs, which tend to spread more rapidly (6).

We hypothesized that the expansion mechanism(s) of ameloblastoma in jaw bone differs from those of invasive cancer cells. In the present study, we compared the expression levels and release of RANKL in ameloblastoma and invasive oral SCC cell lines, to determine its effect on osteoclast differentiation. We also examined the possibility that ameloblastoma could directly resorb bone or dentine minerals. We found that ameloblastoma cells expressed lower amounts of RANKL than oral SCC cells but resorbed bone mineral materials by activation of vacuolar-type $\mathrm{H}^{+}$-ATPase (V-ATPase) and $\mathrm{H}^{+} / \mathrm{Cl}^{-}$exchange transporter 7 (CLC-7) on their plasma membranes.

\section{Materials and methods}

Cell culture. The human ameloblastoma cell line AM-1 was established from a plexiform-type ameloblastoma representing typical features of native cells $(18,19)$. Cells were grown in defined keratinocyte serum-free medium (D-KSFM; Invitrogen, San Diego, CA, USA). Human normal skin keratinocytes (HaCaT), human tongue squamous carcinoma (HSC-3), human lip fibroblasts (KD; purchased from JCRB Cell Bank, Osaka, Japan), and RAW264.7 mouse macrophage cells (purchased from DS Pharma Biomedical, Osaka, Japan) were grown in Dulbecco's modified Eagle's medium (DMEM; Invitrogen), supplemented with $10 \%$ fetal bovine serum (FBS; PAA Laboratories, Pasching, Austria). Human osteoclast (hOC) precursor cells derived from bone marrow (purchased from Lonza, Basel, Switzerland) were grown in an original culture solution based on modified Eagle's medium (MEM) containing 100 ng/ml human synthetic RANKL (Wako Pure Chemical Industries, Ltd., Osaka, Japan) and $50 \mathrm{ng} / \mathrm{ml}$ human macrophage colony stimulating factor (M-CSF; PeproTech, Rocky Hill, NJ, USA). Cells were reseeded for the next passage after trypsin (Invitrogen) dispersion when they reached $\sim 80 \%$ confluency. HaCaT and HSC-3 were gifts from M. Furue (Kyushu University, Fukuoka, Japan) and H. Takeuchi (Kyushu Dental University, Kitakyushu, Japan), respectively.

Western blot analysis. Western blots were performed as previously described (20). Briefly, cells (AM-1, HaCaT, HSC-3 KD and hOCs) were homogenized in $1 \mathrm{ml}$ ice-cold lysis buffer and centrifuged at $50,000 \mathrm{x} \mathrm{g}$ for $30 \mathrm{~min}$ at $4^{\circ} \mathrm{C}$. The supernatants $(20 \mu \mathrm{g})$ were then separated on 10 or $12 \%$ sodium dodecyl sulfate-polyacrylamide gel electrophoresis (SDS-PAGE) gels and transferred to polyvinyldifluoride membranes (Millipore, Darmstadt, Germany). Immunoblot analyses were performed using mouse anti-human RANKL monoclonal antibody (1:500; Sigma-Aldrich, St. Louis, MO, USA), mouse antihuman V-ATPase isoform $\alpha 3$ monoclonal antibody (V-ATPase $\alpha 3$ or TCIRG1; 1:500; Abcam, Cambridge, MA, USA), rabbit anti-human CLC-7 (1:500; Abgent, Inc., San Diego, CA, USA), rabbit anti-human chloride transporter 3 (CLC-3 polyclonal antibody, 1:500; Abcam), or mouse anti-human cathepsin $\mathrm{K}$ monoclonal antibody (1:1,000; Sigma-Aldrich). Rabbit antihuman $\beta$-actin monoclonal antibody (1:1,000; Cell Signaling Technology, Danvers, MA, USA) was used as an internal standard. Blots were developed with horseradish peroxidase (HRP)-linked secondary antibodies (1:3,000; Cell Signaling Technology) and visualized using the enhanced chemiluminescence (ECL) system, LAS-4000 (GE Healthcare, Cleveland, OH, USA). Immobilon western chemiluminescent HRP substrate (Millipore) was used for detection. For the biotinylation assay, cells (AM-1 and HaCaT; 80\% confluent in a $6-\mathrm{cm}$ dish) were lysed in lysis buffer following incubation in cold biotin reagent $(1 \mathrm{mg} / \mathrm{ml}$ sulpho-NHS-SS-biotin; Thermo Fisher Scientific, Waltham, MA, USA) for $30 \mathrm{~min}$ at $4^{\circ} \mathrm{C}$, and centrifuged at $50,000 \mathrm{x}$ g for $30 \mathrm{~min}$ at $4^{\circ} \mathrm{C}$. The supernatant was then incubated with $300 \mu \mathrm{l}$ cold avidin beads (Thermo Fisher Scientific) at $4^{\circ} \mathrm{C}$ for $2 \mathrm{~h}$, followed by centrifugation at $3,500 \mathrm{x}$ g for $30 \mathrm{~min}$ at $4^{\circ} \mathrm{C}$. Supernatants were then aspirated, and the beads were washed three times with $1 \mathrm{ml}$ cold lysis buffer, once with cold $500 \mathrm{mM} \mathrm{NaCl}$ and Tris- $\mathrm{HCl}(\mathrm{pH} 7.5)$, and once with cold $10 \mathrm{mM}$ Tris- $\mathrm{HCl}(\mathrm{pH} 7.5)$. The beads were boiled with $50 \mu 1$ Laemmli sample buffer, and a $20-\mu 1$ aliquot was analyzed by SDS-PAGE. Antibodies used for the immunoblot analysis included anti-V-ATPase $\alpha 3$, anti-CLC-7 and anti-E-cadherin (rabbit anti-human monoclonal; 1:1,000; Cell Signaling Technology).

Coculture and osteoclastogenesis experiments. AM-1 and KD cells were cocultured at a ratio of $1: 1$ in a $6-\mathrm{cm}$ dish in a 1:1 mixture of D-KSFM and 10\% FBS-containing $\alpha$-MEM, as previously described $(5,21)$. Bone marrow cells were collected from C57BL/6J mice at 6 weeks of age. Cells $\left(1.5 \times 10^{5}\right) /$ well in 24 -well plates were cultured in $10 \%$ FBS-containing $\alpha$-MEM with $20 \mathrm{ng} / \mathrm{ml}$ M-CSF. After 2 days, adherent cells were used as bone marrow-derived monocyte/macrophage precursor cells 


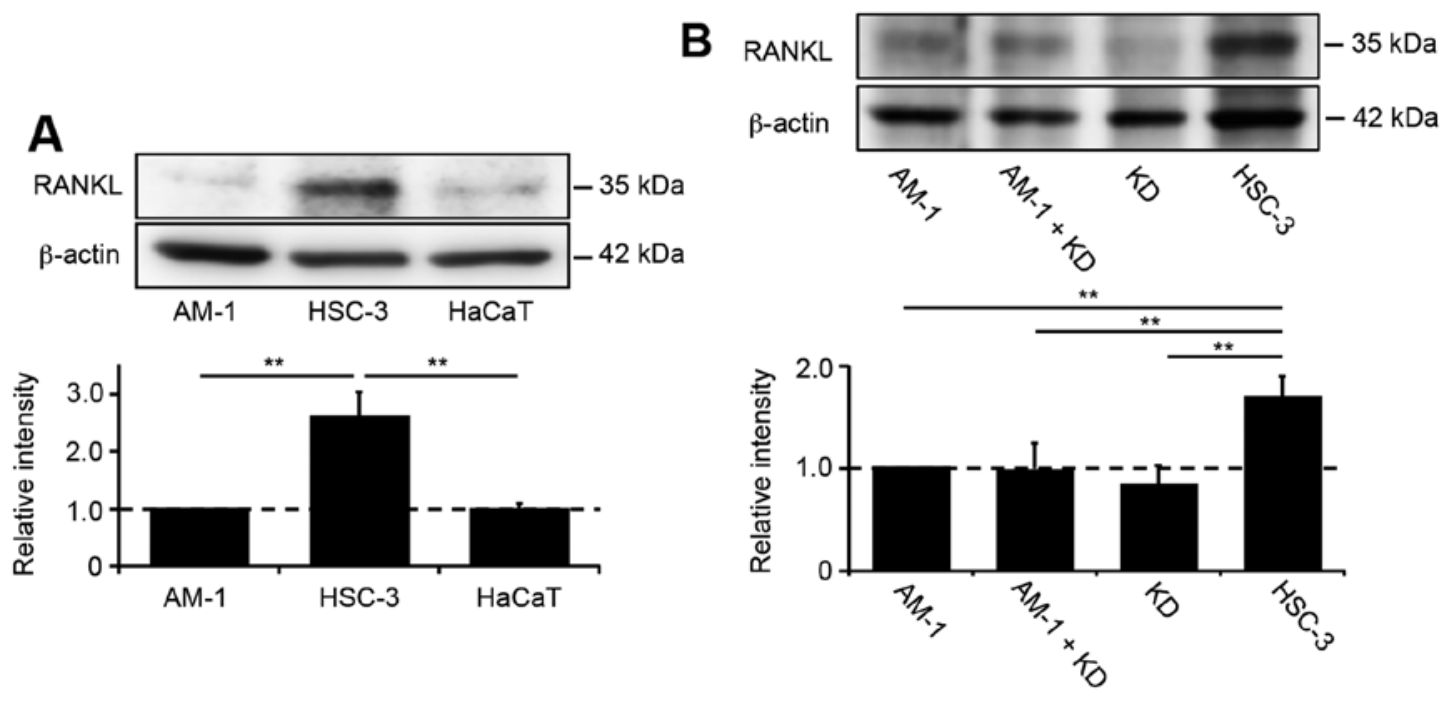

Figure 1. RANKL expression in AM-1, HSC-3 and HaCaT cells. Western blot analysis of RANKL and $\beta$-actin expression in AM-1, HSC-3 and HaCaT cells (A) or in AM-1, coculture of AM-1 and KD, KD and HSC-3 cells (B); representative blots are shown. The density of RANKL expression relative to that of $\beta$-actin is depicted and standardized based on the AM-1 results ( $\mathrm{n}=4$ in each case; A and B). Significant differences as assessed by one-way ANOVA are indicated by ${ }^{* *} \mathrm{P}<0.01$.

(BMM). AM-1 or HSC3 cells were cocultured with RAW264.7 cells or BMM in 24-well plastic plates at a ratio of 1:5 in 5\% FBS-containing $\alpha$-MEM medium ( $\alpha$-MEM), or a mixture of D-KSFM and 10\% FBS-containing $\alpha$-MEM (mixed medium). All media were supplemented with $50 \mathrm{ng} / \mathrm{ml} \mathrm{M-CSF}$. As a positive control, $100 \mathrm{ng} / \mathrm{ml}$ RANKL was added to the media. After 5-7 days, cells were fixed in 4\% paraformaldehyde (PFA), and stained for tartrate-resistant acid phosphatase (TRAP) using a TRAP kit (Sigma-Aldrich). TRAP-positive multinuclear cells containing more than three nuclei were considered to be osteoclasts (22). For assessment of osteoclast differentiation, RAW264.7 cells $\left(5 \times 10^{4}\right.$ cells/well) were cultured in 24-well plates in $\alpha$-MEM. PP2, PP3 (Abcam), and (3Z)-3-[(1-Methylindol-3-yl)methylidene]-2-oxo- $1 H$-indole5 -sulfonamide [spleen tyrosine kinase (Syk) inhibitor (Syk inh); Abcam] were applied $1 \mathrm{~h}$ prior to changing the medium to mixed medium. Recombinant mouse semaphorin $3 \mathrm{~A}$ (R\&D Systems, Minneapolis, MN, USA) was applied $12 \mathrm{~h}$ prior to changing the medium to the mixed medium. The culture medium was changed every second day. After 7 days, cells were fixed in 4\% PFA and stained for TRAP. The method for counting TRAP-positive cells was as described above.

Cell observation and pit assay. Calcium phosphate- and collagen I-coated coverslips, and 24-well calcium phosphatecoated plates (BD BioCoat Osteologic; BD Biosciences, San Jose, CA, USA; and Osteo Assay surface; Corning Incorporated, Corning, NY, USA, respectively) were used for the pit assay (23). AM-1 and HaCaT cells were cultured on Osteologic coverslips for 2-10 days. AM-1 and hOCs were cultured on osteo assay surface plates for 10 days. Cells and pits were observed at magnifications of $4 \mathrm{X}$ and $10 \mathrm{X}$ with an inverted microscope (IX71; Olympus, Tokyo, Japan); images were captured using cellSens imaging software (ver. 1.7.1; Olympus). The pits in three samples were counted in random regions with pit areas quantified using ImageJ software (NIH, Bethesda, MD, USA).
Reverse transcription-polymerase chain reaction (RT-PCR) analysis. Total RNA was extracted from AM-1 using TRIzol reagent (Thermo Fisher Scientific). Isolated total RNA (4 $\mu \mathrm{g})$ was subjected to RT-PCR analysis using PCR Super Mix High Fidelity (Thermo Fisher Scientific) and the CLC-1 primers 5 -ctgagccagcctgtctgtttt-3' (forward) and 5'-ctccaactcgccetc tacctt-3' (reverse); CLC-2 primers 5'-tagccetgaggcttctgtctg-3' (forward) and 5'-ggagcaggatcaattttgcag-3' (reverse); CLC-3 primers 5'-tagggcaaatattgectggtg-3' (forward) and 5'-gatg gaaccttgatgccaaaa-3' (reverse); CLC-4 primers 5'-ctcctcccat acaaagggacac-3' (forward) and $5^{\prime}$-taatgctgtcctcetgtgctgt-3' (reverse); CLC-5 primers $5^{\prime}$-gcatatagcacagatggcgaac-3' (forward) and 5'-acggttggaatttctcttgcat-3' (reverse); CLC-6 primers 5 '-ctggaatgggagacagaggtg-3' (forward) and '5-cctc catggtccagtcttcac-3' (reverse); CLC-7 primers 5'-gactcgtagc accagggtttg-3' (forward) and 5'-catgtgctaggggaagacctg-3' (reverse); CLC-Ka primers 5'-gaggaggtggtcaaggttgtg-3' (forward) and 5'-ttctcaggagctctcactgg-3' (reverse); and $\mathrm{CLC}-\mathrm{Kb}$ primers $5^{\prime}$-gaggaggtggtcaaggttgtg- $3^{\prime}$ (forward) and 5'-tttcttcatctccacccagga-3' (reverse). Total RNA extracted from HEK293 (kindly provided by Dr H. Takeuchi) or human skeletal muscle (Agilent Technologies, Santa Clara, CA, USA) was used as a positive control.

Fluorescent immunohistochemistry. Clinical sample collection was performed at the Department of Oral and Maxillofacial Surgery, Kyushu University Hospital (Fukuoka, Japan). Specimens were removed surgically from three patients with primary ameloblastoma (plexiform, follicular and basal cell types); all patients provided informed consent before enrollment. Immunohistochemistry was performed as previously described (20). Briefly, following the initial biopsy, all specimens were fixed in 4\% PFA in phosphate-buffered saline (pH 7.4) overnight, embedded in paraffin wax and sectioned at $5 \mu \mathrm{m}$. After deparaffinization and blocking procedures, specimens were stained with primary antibodies (mouse anti-human V-ATPase $\alpha 3$ antibody, 1:200; rabbit anti-human CLC-7 

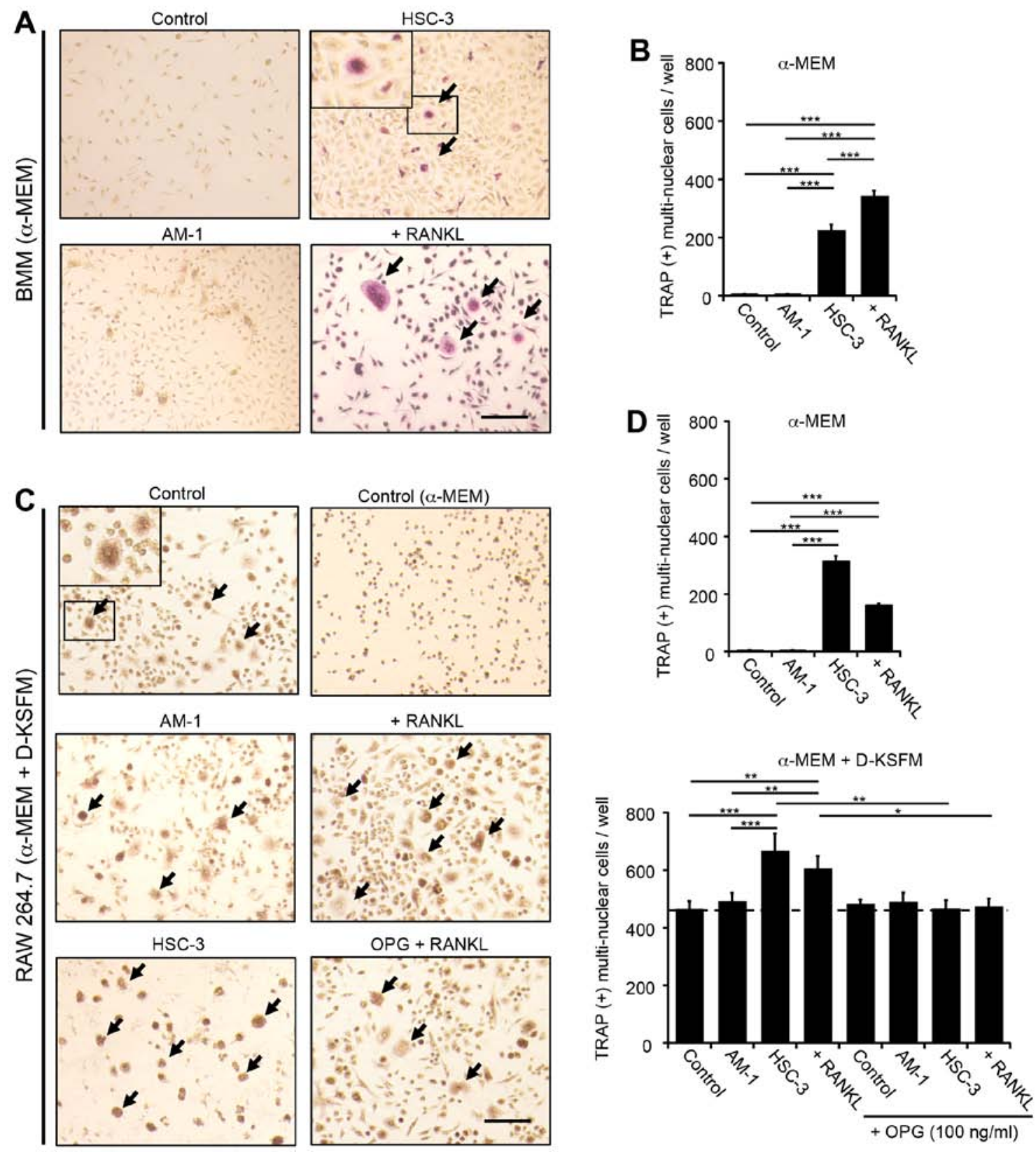

Figure 2. In vitro osteoclastogenesis in BMM and RAW264.7 cells cocultured with either AM-1 or HSC-3 cells. Generation of TRAP-positive cells was determined using an osteoclastogenic assay. BMM were cocultured with AM-1 or HSC-3 cells in $\alpha$-MEM; $100 \mathrm{ng} / \mathrm{ml}$ RANKL was used as a positive control, and the number of TRAP-positive multinuclear cells was counted (A and B). RAW264.7 cells were cocultured with AM-1 or HSC-3 cells in $\alpha$-MEM, mixed medium, or OPG-containing mixed medium; $100 \mathrm{ng} / \mathrm{ml} \mathrm{RANKL}$ was used as a positive control, and the number of TRAP-positive multinuclear cells was counted. Representative images in mixed medium or in $\alpha$-MEM are shown (C). Cell and medium types used are indicated. Results in OPG-containing medium (D). Enlarged image is presented in the inset. Scale bar, $100 \mu \mathrm{m}$. Statistical significance assessed by one-way ANOVA is indicated by ${ }^{*} \mathrm{P}<0.05,{ }^{* *} \mathrm{P}<0.01$ and ${ }^{* * *} \mathrm{P}<0.001$

antibody, 1:200) and secondary antibodies (Alexa Fluor 594 conjugated anti-mouse IgG, HRP-linked antibody, 1:1,000; Alexa Fluor 488 conjugate anti-rabbit IgG, HRP-linked antibody, 1:1,000; Invitrogen). Sections were then mounted using PermaFluor mountant (Lab Vision Products, Thermo Fisher Scientific) and visualized at the appropriate wavelength using a fluorescence microscope (BioRevo BZ-9000; Keyence). For cell staining, AM-1 cells and hOCs were fixed in 4\% PFA. After permeabilization with digitonin $(100 \mu \mathrm{g} / \mathrm{ml}$; Wako Pure Chemical) and blocking with $2.5 \%$ bovine serum albumin (Sigma-Aldrich), cells were stained with the aforementioned primary antibodies (mouse anti-human E-cadherin antibody,
1:200; BD Biosciences; rabbit anti-human CLC-3 antibody, 1:200; Abcam; mouse anti-human V-ATPase $\alpha 3$ antibody, 1:200; rabbit anti-human CLC-7 antibody, 1:200). This was followed by incubation with secondary antibodies, and then mounting with PermaFluor mountant for visualization. Singlecell samples were visualized with a confocal microscope (LSM700; Carl Zeiss, Oberkochen, Germany; or A1; Nikon, Tokyo, Japan). Images were processed using Adobe Photoshop CS3 (Adobe Systems, San Jose, CA, USA).

Drugs. Bafilomycin A1 was obtained from Merck. All other chemicals were purchased from Sigma-Aldrich. 

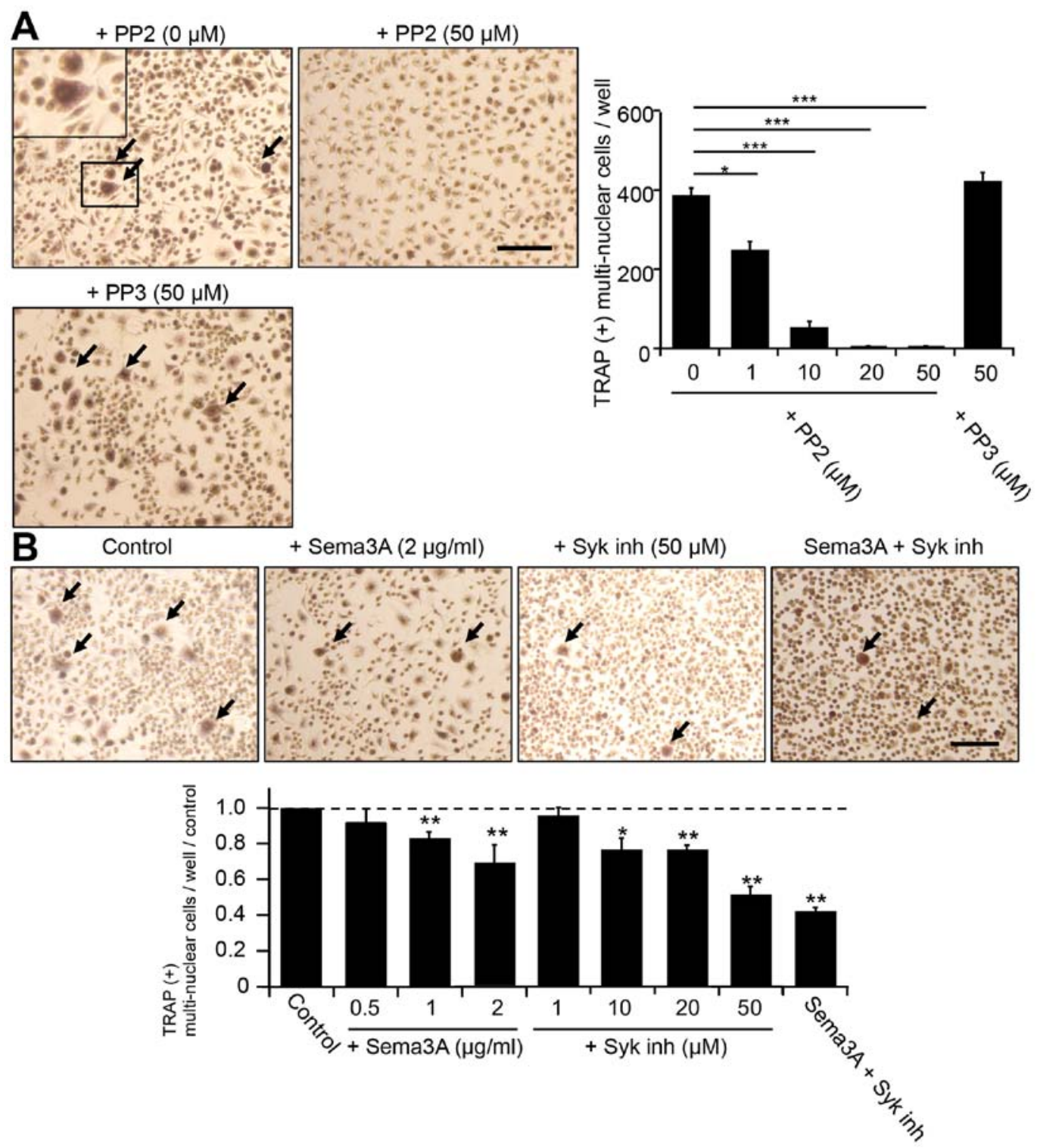

Figure 3. Effects of non-receptor tyrosine kinase inhibitors and semaphorin 3A on D-KSFM-induced osteoclastogenesis. RAW264.7 cells were cultured in 24-well plates in $\alpha$-MEM. Inhibitors of Src (PP2) or Syk were added at the indicated concentrations $1 \mathrm{~h}$ prior to changing the culture medium to mixed medium including each inhibitor. PP3 was used as a negative control for PP2 (A and B). Sema3A was added $12 \mathrm{~h}$ prior to changing the culture medium to mixed medium including the indicated concentrations of sema3A (B). The mixed medium without inhibitors was used as control (B). After 7 days in culture, cells were fixed in 4\% PFA and stained for TRAP ( $\mathrm{n}=3$ or 4 for each). Enlarged image is presented in the inset. Scale bar, $100 \mu \mathrm{m}$. Statistical significance assessed by Student's t-test is indicated by ${ }^{*} \mathrm{P}<0.05,{ }^{* *} \mathrm{P}<0.01$ and ${ }^{* * *} \mathrm{P}<0.001$.

Statistical analyses. All data are expressed as the mean \pm standard error of the mean (SEM). Student's t-test and one-way analysis of variance (ANOVA) were used for statistical evaluations. Statistical significance was set as $\mathrm{P}<0.05$.

\section{Results}

Assessment of bone demineralization and RANKL expression by $A M-1$ cells. Western blot analysis using anti-RANKL antibody was performed to detect expression of RANKL in AM-1, HSC-3 and HaCaT cells. HSC-3, bone invasive cancer cells and $\mathrm{HaCaT}$, normal skin keratinocyte, were used as a positive and negative control, respectively. RANKL expression was high in HSC-3 cells, whereas in AM-1 cells, its expression was similar to that in the negative control (Fig. 1A). To evaluate the effect of tumor-stromal interactions on RANKL expression by ameloblastoma cells, AM-1 and KD cells (human lip fibroblasts) were cocultured in mixed medium, but this did not increase RANKL expression (Fig. 1B). Next, we examined the osteoclastic differentiation of BMM and RAW264.7 cells cocultured with AM-1 or HSC-3 cells grown in a medium of $\alpha$-MEM alone or $\alpha$-MEM plus D-KSFM (mixed medium); as a positive control, $100 \mathrm{ng} / \mathrm{ml}$ RANKL was added to the medium in the absence of coculture cells. TRAP-positive multinuclear cells were detected in the cocultures with HSC-3 cells, but not in those with AM-1 grown in $\alpha$-MEM medium (Fig. 2). On the other hand, cocultures grown in mixed medium produced more TRAP-positive cells, which were inhibited to the control level by the addition of osteoprotegerin (OPG; $100 \mathrm{ng} / \mathrm{ml}$ ) (Fig. 2C and D), indicating the presence of RANKL-independent osteoclastogenesis in the mixed medium. To investigate the RANK-independent 


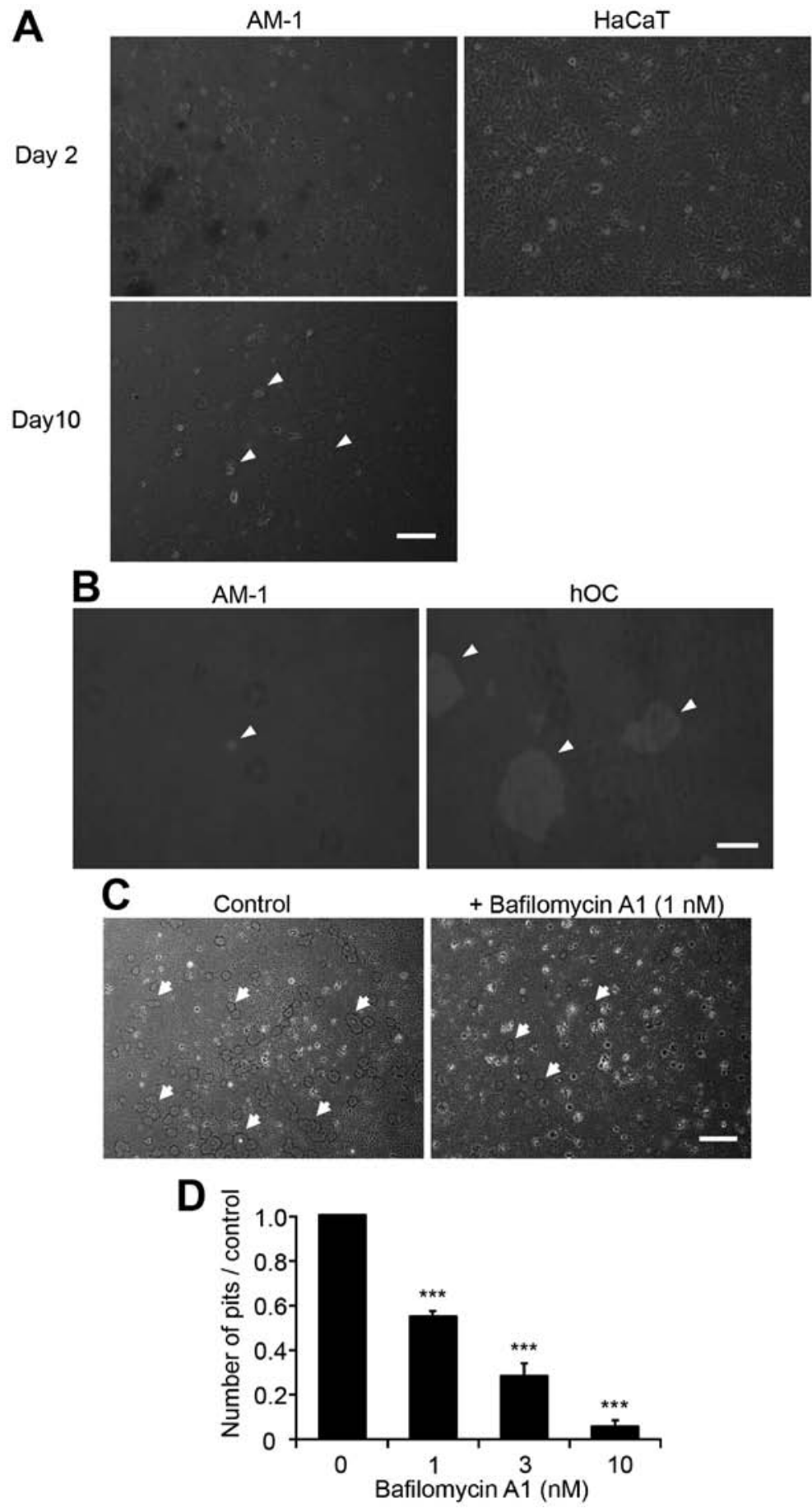

Figure 4. Absorption pit formation by AM-1 cells. (A) AM-1 and HaCaT cells were cultured on Osteologic coverslips for 10 and 2 days, respectively. Arrows indicate the pits formed by AM-1 cells (microscope magnification, x10). Scale bar, $100 \mu \mathrm{m}$. (B) AM-1 and hOCs were cultured on Osteo Assay surface plates for 10 days. Arrows indicate the pits formed by AM-1 cells and hOCs (magnification, x20). Scale bar, $200 \mu \mathrm{m}$. (C) AM-1 cells were cultured in the presence or absence of bafilomycin A1 on Osteologic calcium phosphate- and collagen I-coated discs for 10 days. Arrowheads indicate typical pits demineralized by AM-1 cells. Scale bar, $100 \mu \mathrm{m}$. (D) Inhibitory effect of bafilomycin A1 on demineralization. Statistical significance was analyzed by Student's t-test ( $\mathrm{n}=3$ for each). ${ }^{* * *} \mathrm{P}<0.001$.

osteoclastogenesis of RAW264.7 in mixed medium, we tested several inhibitors of non-receptor tyrosine kinases, which are related to immunoreceptor tyrosine-based activation motif (ITAM)-bearing receptor pathways. PP2, a specific Src kinase family inhibitor, inhibited the formation of TRAP-positive multinuclear cells in a dose-dependent manner (Fig. 3A). In contrast, PP3 $(50 \mu \mathrm{M})$, a negative control for PP2, did not detectably inhibit TRAP-positive multinuclear cell formation. However, semaphorin 3A (sema3A; $>1 \mu \mathrm{g} / \mathrm{ml}$ ), a negative regulator of the formation of plexin-A1-triggering receptor expressed in myeloid cells-2 (TREM-2), which is an immunoreceptor, DNAX activating protein of $12-\mathrm{kDa}$ (DAP12) complex, and Syk inh (50 $\mu \mathrm{M})$ partially inhibited the RANKL-independent TRAP-positive cell formation (Fig. 3). Interestingly, further inhibition was observed by application of a mixture of sema3A (2 $\mu \mathrm{g} / \mathrm{ml})$ and Syk inh $(50 \mu \mathrm{M})$ (Fig. 3B). 


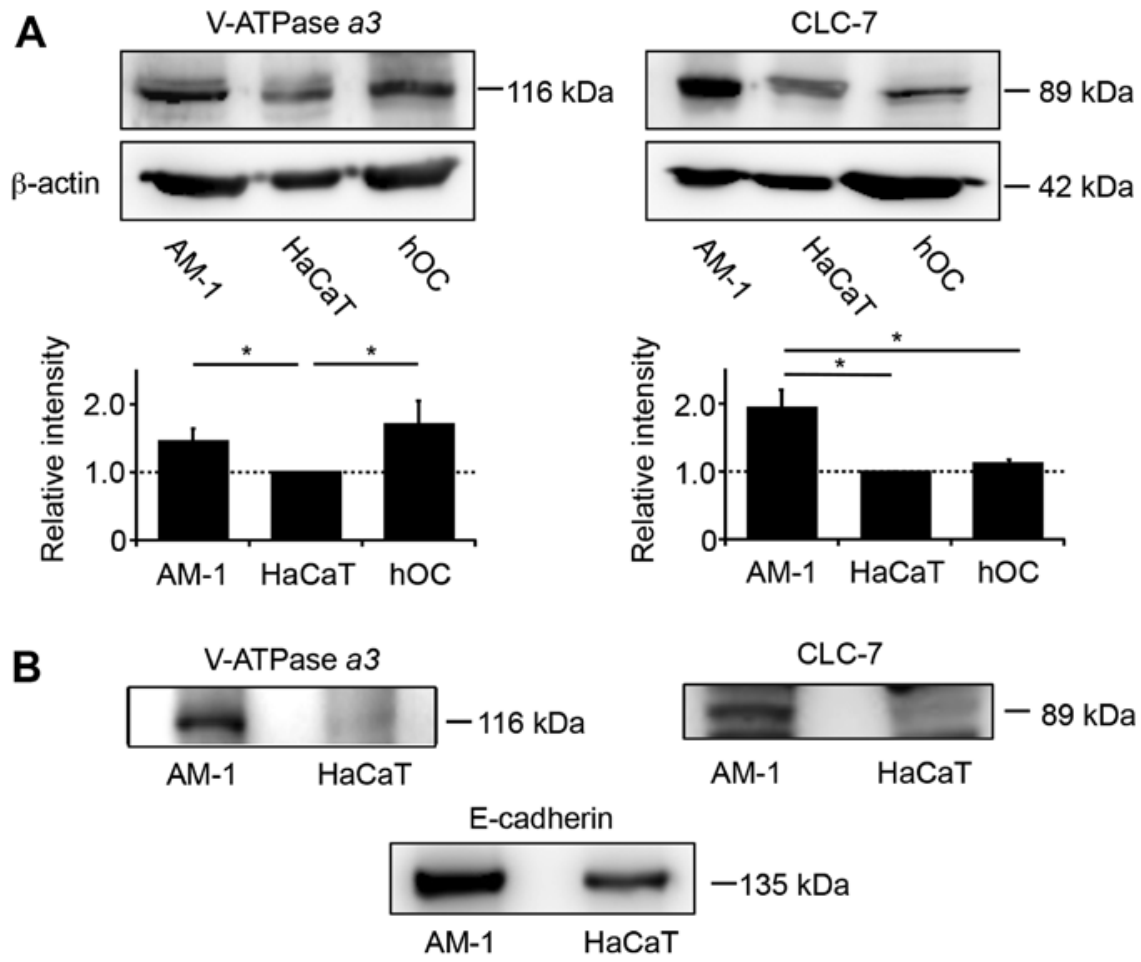

Figure 5. Plasma membrane-specific localization of V-ATPase and CLC-7 in AM-1 cells. (A) Western blot analysis of V-ATPase, CLC-7 and $\beta$-actin in AM-1, $\mathrm{HaCaT}$ and hOC. A typical blot is shown. Band densities of V-ATPase or CLC-7 relative to that of $\beta$-actin, and relative to that in HaCaT cells are shown (n=4 in each case). Statistical significance assessed by one-way ANOVA is indicated by ${ }^{*} \mathrm{P}<0.05$. (B) Biotinylation assay of AM-1 and HaCaT cells. V-ATPase (116 kDa) and CLC-7 (89 kDa) were detected in AM-1, but not in HaCaT cells. E-cadherin (135 kDa) was used as a positive control.

AM-1 cells dissolve the mineral substrate. Based on the above results, we hypothesized that ameloblastoma cells might directly demineralize bone. Their demineralization ability was assessed using calcium phosphate- and collagen I-coated coverslips (Osteologic), which mimic bone mineral substrate. AM-1 cells grew very slowly and more than 10 days were needed to reach $\sim 80 \%$ confluency after an initial seeding of $6.0 \times 10^{5}$ cells in a non-coated $6-\mathrm{cm}$ dish. After reaching confluency, cells $\left(2.0 \times 10^{5}\right.$ cells $)$ were reseeded on Osteologic coverslips in 24-well culture plates and cultured for an additional 10 days. Small round pits with a diameter of 30-40 $\mu \mathrm{m}$ were observed on the coverslips at a density of $47 \pm 3$ pits $/ \mathrm{mm}^{2}$ ( $\mathrm{n}=3$; Fig. 4A, left panel). In contrast, $\mathrm{HaCaT}$ cells grew quickly, similarly to HSC-3 cells, reaching $~ 80 \%$ confluency within 2 days of culture in DMEM containing $10 \%$ FBS. HaCaT cells produced no pits on Osteologic coverslips, even after reaching full confluency (Fig. 4A). Addition of bafilomycin A1, an V-ATPase inhibitor, to the culture medium inhibited pit formation in a dose-dependent manner at concentrations ranging from 1 to $10 \mathrm{nM}$ (Fig. 4C and D). Addition of $10 \mathrm{nM}$ concanamycin, another V-ATPase inhibitor, also completely inhibited pit formation by AM-1 cells (data not shown). Next, we determined the demineralization ability of AM-1 cells compared with hOCs, which were differentiated from bone marrow-derived osteoclast precursor cells using RANKL. AM-1 and hOCs were initially seeded at a density of $1 \times 10^{4}$ cells on Osteologic coverslips. Cells were then cultured for 10 days, and the absorbed pits were analyzed as described above. The mean pit area produced by AM-1 cells was $1.7 \%$ of that produced by hOCs $(0.1 \pm 0.03 \%$ for AM- 1 vs. $5.9 \pm 2.5 \%$ for hOCs; $n=3$ for each treatment; Fig. 4B). The addition of bisphosphonates, either alendronate $(10 \mu \mathrm{M})$ or pamidronate $(10 \mu \mathrm{M})$, which are inhibitors of osteoclasts, had no inhibitory effect on the viability of AM-1 cells, although the RAW264.7 cells were susceptible (data not shown).

V-ATPase and CLC-7 are expressed on the plasma membrane of AM-1 cells. Based on the inhibitory effects of bafilomycin A1 and concanamycin, we assumed that demineralization of calcium phosphate by AM-1 cells could be caused by V-ATPase, a proton pump expressed on the surface of the plasma membrane. V-ATPase is coexpressed with the chloride transporter CLC-7 on the surface of organelles, such as lysosomes, in most eukaryotic cells, and on the plasma membrane of osteoclasts. Western blot analysis of AM-1 cell lysates showed the presence of V-ATPase $\alpha 3$ at levels similar to that of hOCs, while CLC-7 was present at levels greater than those in hOCs and $\mathrm{HaCaT}$ cells. The relative expression of V-ATPase and CLC-7 was hOCs $\approx \mathrm{AM}-1>\mathrm{HaCaT}$ and AM- 1 $>$ hOCs $\approx \mathrm{HaCaT}$, respectively (Fig. 5A). To examine whether these proteins were present on the cell-surface, we labeled intact AM-1 and HaCaT cells with a biotinylation reagent, followed by lysis and detection with streptavidin. Biotinylated V-ATPase $\alpha 3$ and CLC-7 were observed in the cell-surface extracts of only AM-1 cells but were absent in $\mathrm{HaCaT}$ cells (Fig. 5B). As a positive control, E-cadherin, a transmembrane protein in the plasma membrane, was detected in the cellsurface extracts of both AM-1 and $\mathrm{HaCaT}$ cells (Fig. 5B). In addition, the expression profile of the CLC chloride channel family in AM-1 cells was assessed by RT-PCR analysis; the results showed that several mRNA for CLC-2, CLC-3, CLC-7 
$\mathrm{AM}-1$

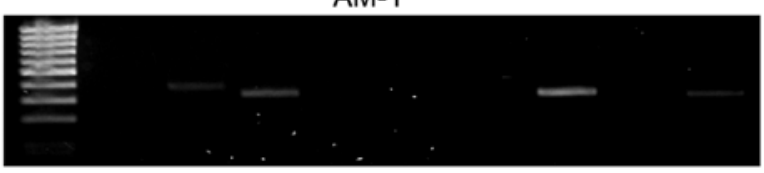

HEK293

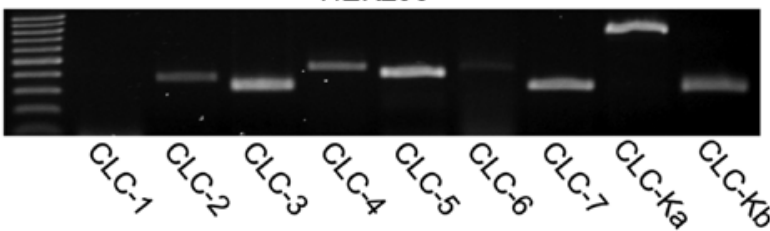

Human

skeletal muscle

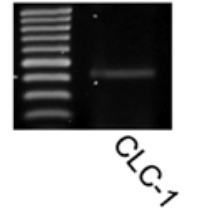

Figure 6. Expression of CLC family genes in AM-1 cells. Expression of CLC family genes in AM-1 cells were analyzed by RT-PCR. CLC-3 and -7 were readily detected; CLC-2 and CLC-Kb were also detected but only at low levels. Total RNA extracted from HEK293 or human skeletal muscle was used as a positive control.

and CLC-Kb were detected (Fig. 6). Immunofluorescence analysis of CLC-3 demonstrated that the positive signals were localized almost entirely in the cytosol of AM-1 cells (Fig. 7).

Comparison of osteoclastogenic features of AM-1 cells and osteoclasts. Immunofluorescence analysis was performed to examine the membrane localization of both V-ATPase $\alpha 3$ and CLC-7 (Fig. 8, Z-axis and tiled images). Merged images of V-ATPase $\alpha 3$ and CLC-7 are shown in Fig. 8C and F. As a positive control, an identical pattern of membrane localization of V-ATPase $\alpha 3$ and CLC-7 was evident in hOC (Fig. 9A). Nevertheless, the cytosol of both AM-1 cells and hOCs was also stained by antibodies for V-ATPase $\alpha 3$ and CLC-7, because these factors are usually expressed in the lysosomes of all eukaryotic cells (Figs. 8 and 9A). Next, we performed TRAP staining of AM-1 cells. AM-1 cells were negative for TRAP, in clear contrast to the findings for osteoclasts (data not shown). Furthermore, neither AM-1 nor HaCaT cells expressed cathepsin $\mathrm{K}$, a cysteine proteinase released from osteoclasts to digest the organic materials of bone (Fig. 9B).

Distribution of V-ATPase and CLC-7 in clinical specimens of ameloblastoma lesions. Finally, we performed immunofluorescence staining of clinically dissected specimens from patients bearing three types of ameloblastoma: plexiform, follicular and basal cell types. All types of solid/multicystic ameloblastoma specimens were clearly stained with V-ATPase $\alpha 3$ and CLC-7 antibodies in the cytosol, particularly on the plasma membrane of the epithelium rather than the stroma (Fig. 10).

\section{Discussion}

Disruptive bone resorption as a result of invasion by cancer cells is caused by maturation and functional activation of osteoclasts by RANKL released from cancer cells $(7,24,25)$. Ameloblastoma cells are thought to behave in a similar

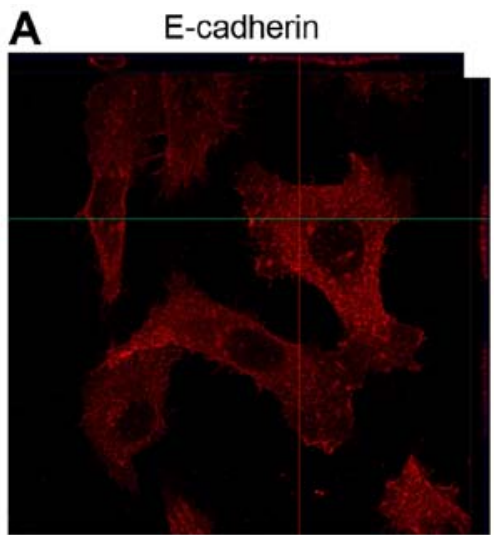

D

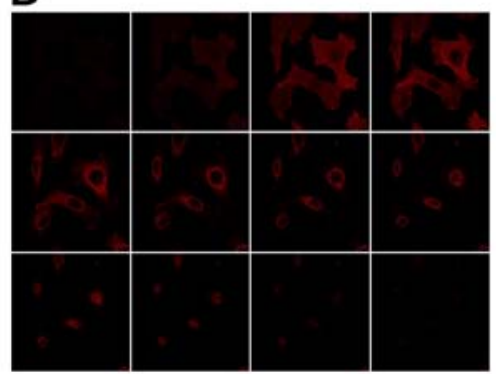

B

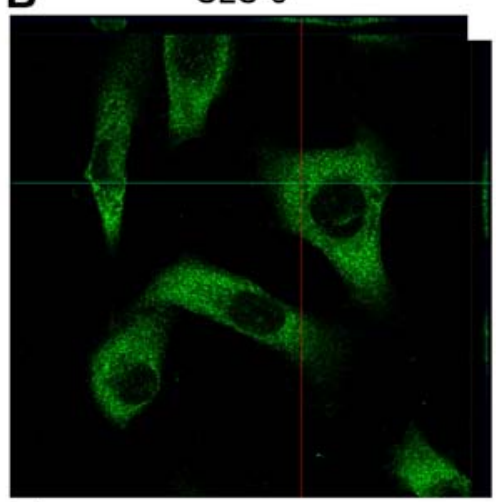

E

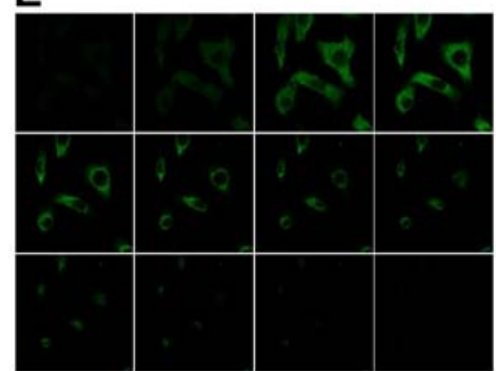

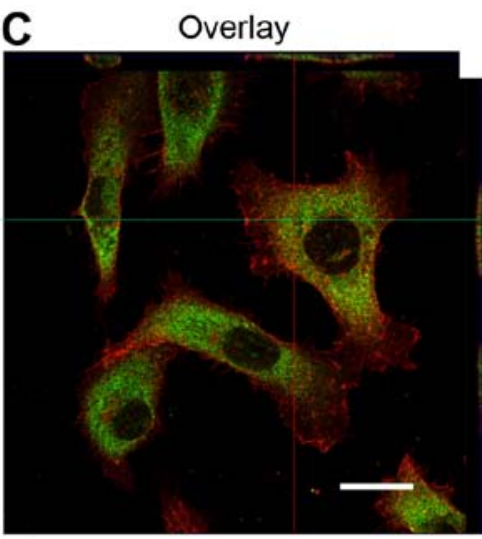

$\mathbf{F}$

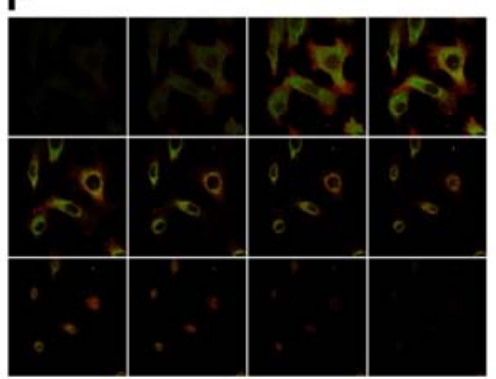

Figure 7. Localization of CLC-3 in AM-1 cells. Immunofluorescence analysis of E-cadherin (red; A ) and CLC-3 (green; B) in AM-1 cells. Cells were cultured on non-coated coverslips and fixed with 4\% PFA. Merged images are shown in C. The upper right portion of each image depicts Z-axis sliced images at the green and red lines, respectively. Scale bar, $20 \mu \mathrm{m}$. Images D, E and F represent Z-axis sliced images of A, B, and C, respectively. Sliced images were taken at $0.4-\mu \mathrm{m}$ intervals. 


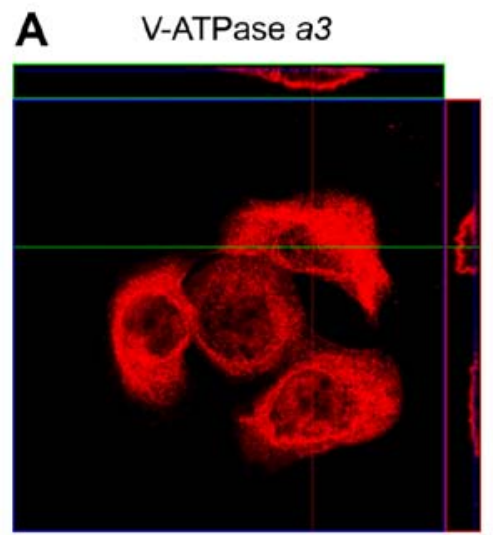

D

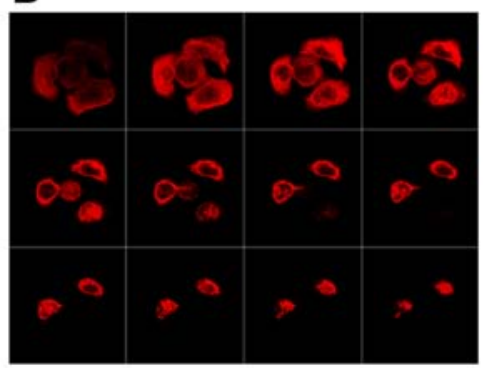

B

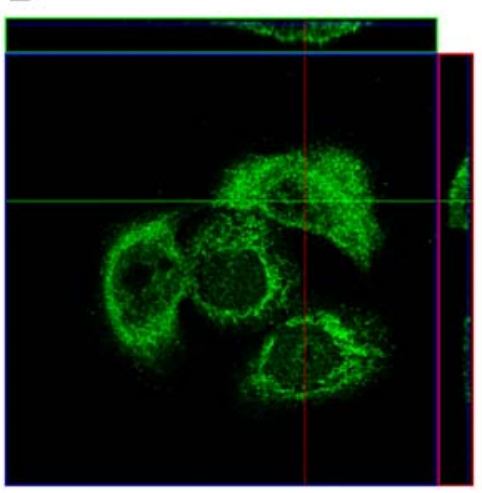

$\mathrm{E}$

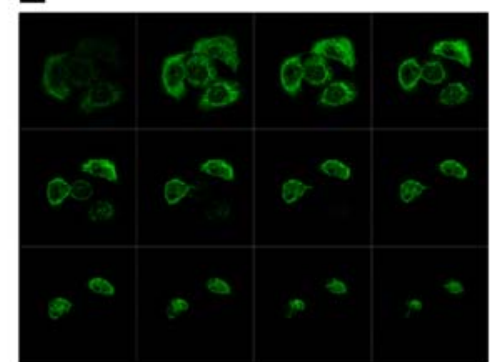

C Overlay

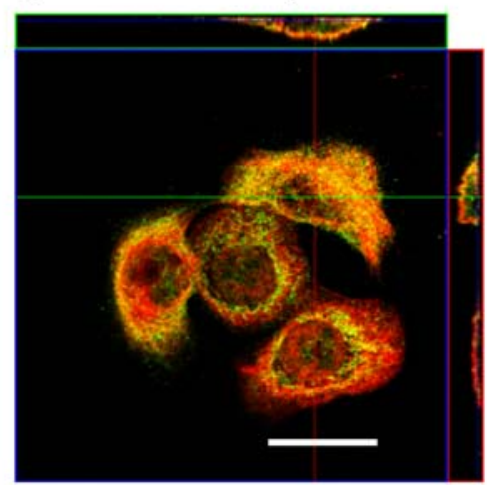

$\mathbf{F}$

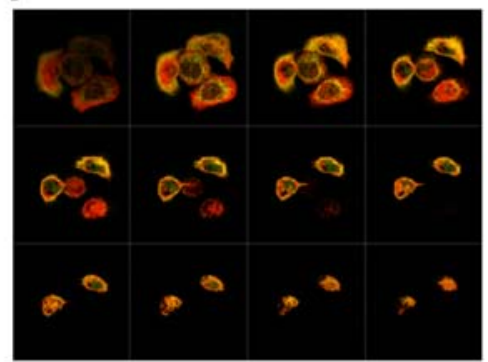

Figure 8. Localization of V-ATPase and CLC-7 in AM-1, and TRAP staining of AM-1 and human osteoclasts. Immunofluorescence analysis of V-ATPase $\alpha 3$ (red; A) and CLC-7 (green; B) in AM-1 cells. Cells were cultured on non-coated coverslips and fixed. Merged images are shown in C. The upper right portion of each image depicts Z-axis sliced images at the green and red lines, respectively. Scale bar, $20 \mu \mathrm{m}$. Images D, E and F are Z-axis sliced images of A, B and $\mathrm{C}$, respectively. Sliced images were taken at $0.4-\mu \mathrm{m}$ intervals.
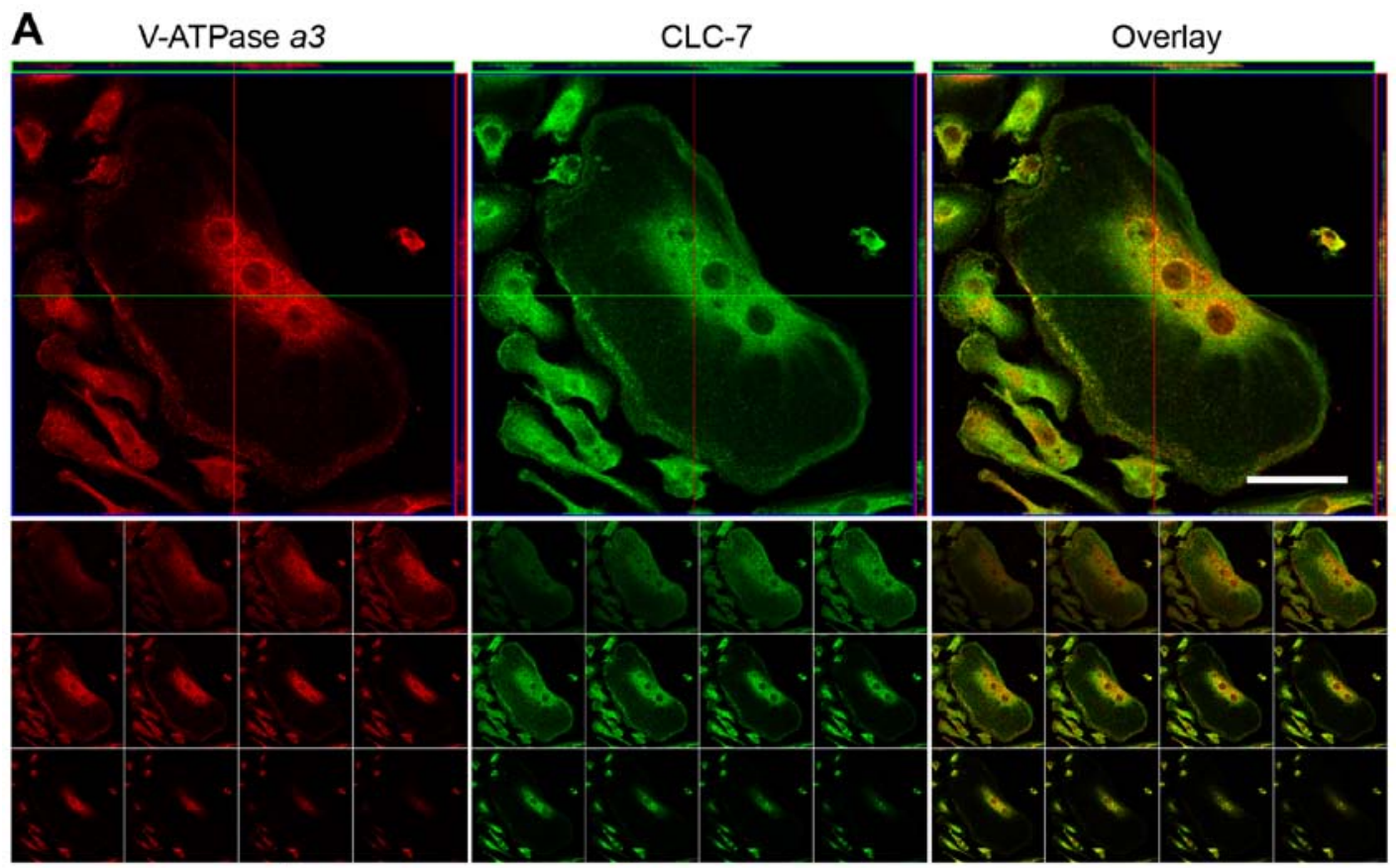

B

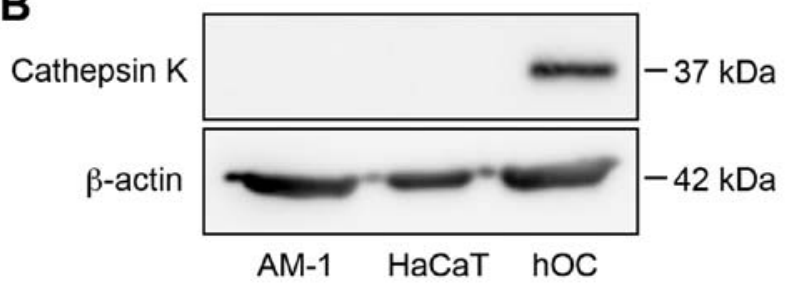

Figure 9. Immunofluorescence analysis of V-ATPase and CLC-7 in human osteoclasts. (A) Immunofluorescence analysis of V-ATPase $\alpha 3$ (red) and CLC-7 (green) in hOCs. Scale bar, $20 \mu \mathrm{m}$. Sliced images were taken at $0.35-\mu \mathrm{m}$ intervals. (B) Western blot analysis of cathepsin $\mathrm{K}$ in AM-1, HaCaT and hOCs. 


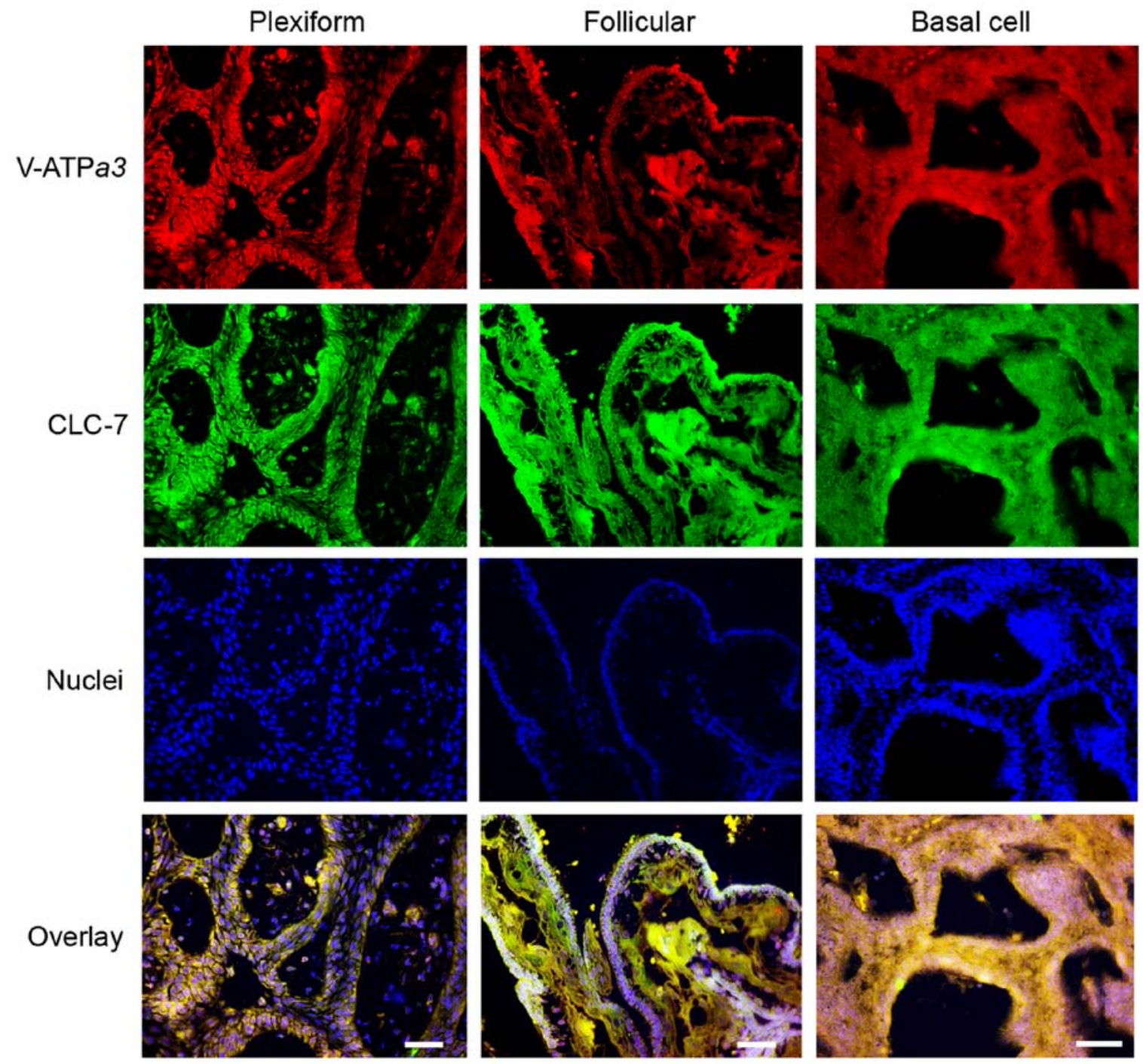

Figure 10. Distribution of V-ATPase and CLC-7 in several types of ameloblastoma. Immunohistochemical analyses were performed using mouse anti-human V-ATPase $\alpha 3$ (1:200; top, red), rabbit anti-human CLC-7 (1:200; second, green) antibodies, and Hoechst 33342 (1:500; third, blue) in human plexiform, follicular, and basal cell-type ameloblastomas. Merged images (bottom) show colocalization of V-ATPase, CLC-7 and Hoechst 33342. An Alexa Fluor 594-conjugated anti-mouse IgG HRP-linked antibody $(1: 1,000)$ and 488-conjugated anti-rabbit IgG HRP-linked antibody $(1: 1,000)$ were used as secondary antibodies. Scale bar, $200 \mu \mathrm{m}$.

manner, expressing RANKL on the plasma membrane, thereby activating peripheral osteoclasts (5), suggesting that the mechanisms for ameloblastoma expansion in jaw bone are similar to those of bone-invasive cancers. However, despite these apparent similarities, the clinical features of bone cancer and ameloblastoma are quite different $(3,6)$, which led us to examine the osteoclastogenic responses induced by ameloblastoma cells. We found that the expression and release of RANKL by AM-1 cells, an ameloblastoma cell line, appeared to be too low to activate osteoclasts, even in the presence of other cell types such as fibroblasts. Many reports have highlighted the importance of the tumor-stroma interaction in tumor cell invasion, and the role of osteoclastogenesis in odontogenic tumors; however, no increases in RAW264.7 differentiation or RANKL expression in AM-1 were observed in cocultures with AM-1 or KD cells, respectively (26-30). In fact, Kumamoto and Ooya (31) reported little expression of RANKL in either plexiform or follicular ameloblastoma specimens. In addition, RANKL-positive cells were shown by qualitative and quantitative analysis of immunoreactivity to be distributed more commonly throughout the stroma rather than in the epithelium surrounding the ameloblastoma (32). RANKL and OPG positive cells were also more commonly found in the stromal cells of ameloblastoma, implying that RANKL expression in ameloblastoma may play a key role in the proliferation and tumor progression of associated stromal cells, similar to that seen in breast cancer $(33,34)$.

However, Sandra et al (5) and Kibe et al (21) demonstrated osteoclastic differentiation in cocultures of RAW264.7 macrophages with AM-3 cells, a follicular-type ameloblastoma cell line, and with AM-1 cells, results that differ from those of the present study. Differences in the culture medium used in the present study may be a possible explanation for this difference: untreated RAW264.7 cells cultured in a mixed medium ( $\alpha$-MEM plus D-KSFM) alone, which was used in the studies by both Sandra et al (5) and Kibe et al (21), differentiated into TRAP-positive multinuclear cells. In contrast, when cultured in $\alpha$-MEM alone, BMM and RAW246.7 cells did not 
differentiate into TRAP-positive cells without the support of HSC-3 cells or added RANKL. Recently, it has been identified that osteoclastic differentiation comprises two different types of receptor-mediated signaling pathways, including both RANK and immunoreceptor tyrosine-based activation motif (ITAM)-bearing receptors (35). ITAM-bearing receptors are classified into two types: Fc receptor common $\gamma$ subunit $(\mathrm{FcR} \gamma)$ receptors [osteoclast-associated receptor (OSCAR) and paired immunoglobulin-like receptor-A (PIR-A)] and DAP12 receptors [signal-regulatory protein b1 (SIRP $\beta 1)$ and TREM-2]. ITAM-bearing receptors commonly activate phosphorylation of Syk and Src kinases, which are members of the non-receptor tyrosine kinase family (36). The present study showed that osteoclast formation by RAW264.7 in a mixed medium was completely inhibited by PP2 $(>20 \mathrm{mM})$. Src kinases are related not only to the activation of ITAM-bearing receptors, but also to activation of M-CSF receptors $(37,38)$. $\mathrm{M}-\mathrm{CSF}$ and its receptors are involved in an initial step of differentiation (38). Consequently, an Src kinase inhibitor fully suppressed osteoclastic differentiation, while sema3A $(>1 \mu \mathrm{g} / \mathrm{ml})$, a negative regulator of plexin-1A-TREM-2-DAP12 complex formation, and Syk inh $(50 \mu \mathrm{M})$, an inhibitor of FcR, partially inhibited RAW264.7 differentiation $(39,40)$. Together, these results indicate that sema3A suppresses DAP12 receptor signaling, while Syk inh suppresses FcR $\gamma$ signaling. Therefore, we conclude that the D-KSFM used in the previous studies $(5,21)$ must contain some ligands for M-CSF receptors and ITAM-bearing receptors, thus promoting osteoclastogenesis.

From these observations, we hypothesized that ameloblastoma might itself be able to resorb bone, given the fact that their radiographic images show well-defined tumor margins and knife-edge-like dental root resorption, in clear contrast to the images of bone-invasive cancers (1). We speculate that there is little space for osteoclasts to exist between the peritumor wall of ameloblastoma and the dental roots, a feature that is far more typical of ameloblastoma than that of other bone-related tumors. We demonstrated that AM-1 cells formed resorption pits even in the absence of osteoclastic cells, and at a magnitude much greater than that of osteoclasts alone, indicating the probable activation of V-ATPase and CLC-7 expressed on their plasma membranes. Thus, AM-1 exhibited bone demineralization activities similar to osteoclasts. However, AM-1 showed differing features from osteoclasts with regard to the absence of TRAP staining, the insensitivity to bisphosphonates and lack of cathepsin K expression. These results support direct bone demineralization of AM-1, but not experimental contamination of osteoclasts.

In osteoclasts, the $\alpha 3$ subunit of V-ATPase is thought to be essential for bone resorption (41-44), because its absence results in autosomal recessive osteopetrosis $(45,46)$. We thus examined the $\alpha 3$ subunit as a marker of V-ATPase on the plasma membrane of AM-1 cells and clinical specimens. V-ATPase inhibitors bafilomycin A1 and concanamycin effectively blocked pit formation, indicating that AM-1 cells have the ability to resorb calcium phosphate with V-ATPase, a mechanism similar to that of osteoclasts. However, CLC-7 is also a key regulator of bone demineralization, releasing $\mathrm{Cl}^{-}$in cooperation with $\mathrm{H}^{+}$release by V-ATPase in osteoclasts (44). We also detected CLC-7 expression on the plasma membrane of both AM-1 cells and ameloblastoma clinical specimens.
Thus, we showed that ameloblastoma cells demineralized bone matrix by means of V-ATPase and CLC-7 expressed on their plasma membranes. Among CLC chloride channel family members, $\mathrm{CLC}-1,2, \mathrm{Ka}$ and $\mathrm{Kb}$ are classified into voltage-activated chloride channels, while CLC-3, 4, 5, 6 and 7 as chloride transporters. An isotype of these chloride transporter proteins, CLC-3, acts as a main chloride transporter in the endosomes and lysosomes of ameloblastoma cells and other cell types (47).

Taken together, these data show that ameloblastoma cells appear to resorb bone in a manner similar to that of osteoclasts, but at only $1.7 \%$ of the activity. Furthermore, AM- 1 cells grew considerably slower than other cell lines, such as $\mathrm{HaCaT}$ and HSC-3, a phenotype likely related to their slow expansion in the jaw bone. The organic bone matrix consists of collagen, bone Gla protein, bone sialoprotein and other proteins. This complex is degraded by several MMP (MMP-1, MMP-2 and MMP-9), which are released from ameloblastoma, but the cathepsin $\mathrm{K}$ released from osteoclasts was not found in ameloblastoma $(9,10,12-14,46)$. Remarkably, both MMP-2 and MMP-9 are abundantly expressed in AM-1 and AM-3 cells relative to their expression in other oral cancer cells $(21,48)$. These findings appear to suggest that ameloblastoma can resorb bone and dental roots, including the periapical tissue, in concert with their activity in resorption of inorganic hard tissues.

In conclusion, we demonstrated direct bone demineralization, possibly by activation of V-ATPase plus CLC-7 present on the plasma membrane of ameloblastoma rather than by RANKL release by ameloblastoma cells, and therefore we propose a new concept for the slow pathophysiological progression of several typical types of ameloblastomas.

\section{Acknowledgements}

The present study was supported by a Grant-in-Aid for Scientific Research from the Japan Society for the Promotion of Science (KAKENHI, \#24592991 to H.M.,\#26861732 to Y.I. and \#24229009 to M.H.). We would like to thank Professors K. Okabe and $\mathrm{H}$. Takeuchi for critical comments and Professors T. Furue and $\mathrm{H}$. Takeuchi for providing us with $\mathrm{HaCaT}$ and HSC-3 cells, respectively. We also thank Drs M. Matsuda, H. Umebayashi, T. Kawakubo-Yasukochi, A. Mizokami, $\mathrm{H}$. Kondo and S. Kanda for the helpful comments and technical assistance. We would also like to thank the Research Support Center, Graduate School of Medical Sciences, Kyushu University for technical support in using the Carl Zeiss LSM700 and Nikon A1 laser scanning confocal microscopes.

\section{References}

1. Thompson L: World Health Organization classification of tumours: Pathology and genetics of head and neck tumours. Ear Nose Throat J 85: 74, 2006.

2. Hertog D, Bloemena E, Aartman IHA and van-der-Waal I: Histopathology of ameloblastoma of the jaws; some critical observations based on a 40 years single institution experience. Med Oral Patol Oral Cir Bucal 17: e76-e82, 2012.

3. Reichart PA, Philipsen HP and Sonner S: Ameloblastoma: Biological profile of 3677 cases. Eur J Cancer B Oral Oncol 31B: 86-99, 1995.

4. Hong J, Yun PY, Chung IH, Myoung H, Suh JD, Seo BM, Lee JH and Choung PH: Long-term follow up on recurrence of 305 ameloblastoma cases. Int J Oral Maxillofac Surg 36: 283-288, 2007. 
5. Sandra F, Hendarmin L, Kukita T, Nakao Y, Nakamura N and Nakamura S: Ameloblastoma induces osteoclastogenesis: A possible role of ameloblastoma in expanding in the bone. Oral Oncol 41: 637-644, 2005

6. Hirshberg A, Shnaiderman-Shapiro A, Kaplan I and Berger R: Metastatic tumours to the oral cavity - pathogenesis and analysis of 673 cases. Oral Oncol 44: 743-752, 2008.

7. Jimi E, Shin M, Furuta H, Tada Y and Kusukawa J: The RANKL/ RANK system as a therapeutic target for bone invasion by oral squamous cell carcinoma (Review). Int J Oncol 42: 803-809, 2013.

8. Casimiro S, Mohammad KS, Pires R, Tato-Costa J, Alho I, Teixeira R, Carvalho A, Ribeiro S, Lipton A, Guise TA, et al: RANKL/RANK/MMP-1 molecular triad contributes to the metastatic phenotype of breast and prostate cancer cells in vitro. PLoS One 8: e63153, 2013.

9. Souza Freitas V, Ferreira de Araújo CR, Alves PM, de Souza LB, Galvão HC and de Almeida Freitas R: Immunohistochemical expression of matrilysins (MMP-7 and MMP-26) in ameloblastomas and adenomatoid odontogenic tumors. Oral Surg Ora Med Oral Pathol Oral Radiol Endod 108: 417-424, 2009.

10. Ribeiro BF, Iglesias DPP, Nascimento GJF, Galvão HC, Medeiros AM and Freitas RA: Immunoexpression of MMPs-1, -2 , and -9 in ameloblastoma and odontogenic adenomatoid tumor. Oral Dis 15: 472-477, 2009.

11. Zhang B, Zhang J, Xu ZY and Xie HL: Expression of RECK and matrix metalloproteinase-2 in ameloblastoma. BMC Cancer 9: 427, 2009.

12. Qian Y and Huang HZ: The role of RANKL and MMP-9 in the bone resorption caused by ameloblastoma. J Oral Pathol Med 39: 592-598, 2010.

13. Shen LC, Chen YK, Hsue SS and Shaw SY: Expression of osteonectin/secreted protein acidic and rich in cysteine and matrix metalloproteinases in ameloblastoma. J Oral Pathol Med 39: 242-249, 2010

14. Henriques ÁCG, Vasconcelos MG, Galvão HC, de Souza LB and de Almeida Freitas R: Comparative analysis of the immunohistochemical expression of collagen IV, MMP-9, and TIMP-2 in odontogenic cysts and tumors. Oral Surg Oral Med Oral Pathol Oral Radiol Endod 112: 468-475, 2011.

15. Sharma M, Sah P, Sharma SS and Radhakrishnan R: Molecular changes in invasive front of oral cancer. J Oral Maxillofac Pathol 17: 240-247, 2013

16. Whitehouse GH: Radiological bone changes produced by intraoral squamous carcinomata involving the lower alveolus. Clin Otolaryngol Allied Sci 1: 45-52, 1976.

17. Murrin RJA and Mahendra P: 'Floating' teeth at presentation in sporadic Burkitt's lymphoma. Br J Haematol 127: 1, 2004.

18. Harada H, Mitsuyasu T, Nakamura N, Higuchi Y, Toyoshima K, Taniguchi A and Yasumoto S: Establishment of ameloblastoma cell line, AM-1. J Oral Pathol Med 27: 207-212, 1998.

19. Sweeney RT, McClary AC, Myers BR, Biscocho J, Neahring L, Kwei KA, Qu K, Gong X, Ng T, Jones CD, et al: Identification of recurrent SMO and BRAF mutations in ameloblastomas. Nat Genet 46: 722-725, 2014.

20. Sugihara M, Morita H, Matsuda M, Umebayashi H, Kajioka S, Ito S, Nishida M, Inoue R, Futatsuki T, Yamazaki J, et al: Dual signaling pathways of arterial constriction by extracellular uridine 5'-triphosphate in the rat. J Pharmacol Sci 115: 293-308, 2011.

21. Kibe T, Fuchigami T, Kishida M, Iijima M, Ishihata K, Hijioka H, Miyawaki A, Semba I, Nakamura N, Kiyono T, et al: A novel ameloblastoma cell line (AM-3) secretes MMP-9 in response to Wnt-3a and induces osteoclastogenesis. Oral Surg Oral Med Oral Pathol Oral Radiol 115: 780-788, 2013.

22. Tsutsumi K, Matsuda M, Kotani M, Mizokami A, Murakami A, Takahashi I, Terada Y, Kanematsu T, Fukami K, Takenawa T, et al: Involvement of PRIP, phospholipase C-related, but catalytically inactive protein, in bone formation. J Biol Chem 286: 31032-31042, 2011.

23. Loomer PM, Ellen RP and Tenenbaum HC: Osteogenic and osteoclastic cell interaction: Development of a co-culture system. Cell Tissue Res 294: 99-108, 1998.

24. Thomas RJ, Guise TA, Yin JJ, Elliott J, Horwood NJ, Martin TJ and Gillespie MT: Breast cancer cells interact with osteoblasts to support osteoclast formation. Endocrinology 140: 4451-4458, 1999.
25. Michigami T, Ihara-Watanabe M, Yamazaki M and Ozono K: Receptor activator of nuclear factor kappaB ligand (RANKL) is a key molecule of osteoclast formation for bone metastasis in a newly developed model of human neuroblastoma. Cancer Res 61: 1637-1644, 2001.

26. Blankenstein $\mathrm{T}$ : The role of tumor stroma in the interaction between tumor and immune system. Curr Opin Immunol 17: $180-186,2005$.

27. Bhowmick NA and Moses HL: Tumor-stroma interactions Curr Opin Genet Dev 15: 97-101, 2005

28. Guzmán-Medrano R, Arreola-Rosales RL, Shibayama M, Silva-Olivares DA, Bologna-Molina R and Rodríguez MA: Tumor-associated macrophages and angiogenesis: A statistical correlation that could reflect a critical relationship in ameloblastoma. Pathol Res Pract 208: 672-676, 2012.

29. Fuchigami T, Kibe T, Koyama H, Kishida S, Iijima M, Nishizawa Y, Hijioka H, Fujii T, Ueda M, Nakamura N, et al: Regulation of IL- 6 and IL-8 production by reciprocal cell-tocell interactions between tumor cells and stromal fibroblasts through IL-1 $\alpha$ in ameloblastoma. Biochem Biophys Res Commun 451: 491-496, 2014

30. Wang HC, Jiang WP, Sima ZH and Li TJ: Fibroblasts isolated from a keratocystic odontogenic tumor promote osteoclastogenesis in vitro via interaction with epithelial cells. Oral Dis 21: 170-177, 2015.

31. Kumamoto H and Ooya K: Expression of parathyroid hormonerelated protein (PTHrP), osteoclast differentiation factor (ODF)/receptor activator of nuclear factor-kappaB ligand (RANKL) and osteoclastogenesis inhibitory factor (OCIF)/ osteoprotegerin (OPG) in ameloblastomas. J Oral Pathol Med 33: 46-52, 2004.

32. da Silva TA, Batista AC, Mendonça EF, Leles CR, Fukada S and Cunha FQ: Comparative expression of RANK, RANKL, and OPG in keratocystic odontogenic tumors, ameloblastomas, and dentigerous cysts. Oral Surg Oral Med Oral Pathol Oral Radiol Endod 105: 333-341, 2008.

33. Schramek D, Leibbrandt A, Sigl V, Kenner L, Pospisilik JA, Lee HJ, Hanada R, Joshi PA, Aliprantis A, Glimcher L, et al: Osteoclast differentiation factor RANKL controls development of progestin-driven mammary cancer. Nature 468: 98-102, 2010.

34. Gonzalez-Suarez E, Jacob AP, Jones J, Miller R, RoudierMeyer MP, Erwert R, Pinkas J, Branstetter D and Dougall WC: RANK ligand mediates progestin-induced mammary epithelial proliferation and carcinogenesis. Nature 468: 103-107, 2010

35. Koga T, Inui M, Inoue K, Kim S, Suematsu A, Kobayashi E, Iwata T, Ohnishi H, Matozaki T, Kodama T, et al: Costimulatory signals mediated by the ITAM motif cooperate with RANKL for bone homeostasis. Nature 428: 758-763, 2004.

36. Bradshaw JM: The Src, Syk, and Tec family kinases: Distinct types of molecular switches. Cell Signal 22: 1175-1184, 2010.

37. Saltel F, Chabadel A, Zhao Y, Lafage-Proust MH, Clézardin P, Jurdic $\mathrm{P}$ and Bonnelye E: Transmigration: A new property of mature multinucleated osteoclasts. J Bone Miner Res 21: 1913-1923, 2006.

38. Redlich K and Smolen JS: Inflammatory bone loss: Pathogenesis and therapeutic intervention. Nat Rev Drug Discov 11: 234-250, 2012.

39. Hayashi M, Nakashima T, Taniguchi M, Kodama $T$, Kumanogoh A and Takayanagi H: Osteoprotection by semaphorin 3A. Nature 485: 69-74, 2012.

40. Lai JY, Cox PJ, Patel R, Sadiq S, Aldous DJ, Thurairatnam S, Smith K, Wheeler D, Jagpal S, Parveen S, et al: Potent small molecule inhibitors of spleen tyrosine kinase (Syk). Bioorg Med Chem Lett 13: 3111-3114, 2003.

41. Toyomura T, Oka T, Yamaguchi C, Wada Y and Futai M: Three subunit a isoforms of mouse vacuolar $\mathrm{H}^{+}$-ATPase. Preferential expression of the $\alpha 3$ isoform during osteoclast differentiation. J Biol Chem 275: 8760-8765, 2000.

42. Toyomura T, Murata Y, Yamamoto A, Oka T, Sun-Wada GH, Wada Y and Futai M: From lysosomes to the plasma membrane: Localization of vacuolar-type $\mathrm{H}^{+}$-ATPase with the $\alpha 3$ isoform during osteoclast differentiation. J Biol Chem 278: 22023 22030, 2003

43. Forgac M: Vacuolar ATPases: Rotary proton pumps in physiology and pathophysiology. Nat Rev Mol Cell Biol 8: 917-929, 2007. 
44. Matsumoto N, Daido S, Sun-Wada GH, Wada Y, Futai M and Nakanishi-Matsui M: Diversity of proton pumps in osteoclasts: V-ATPase with a3 and d2 isoforms is a major form in osteoclasts. Biochim Biophys Acta 1837: 744-749, 2014.

45. Frattini A, Orchard PJ, Sobacchi C, Giliani S, Abinun M, Mattsson JP, Keeling DJ, Andersson AK, Wallbrandt P, Zecca L, et al: Defects in TCIRG1 subunit of the vacuolar proton pump are responsible for a subset of human autosomal recessive osteopetrosis. Nat Genet 25: 343-346, 2000.

46. Sobacchi C, Schulz A, Coxon FP, Villa A and Helfrich MH: Osteopetrosis: Genetics, treatment and new insights into osteoclast function. Nat Rev Endocrinol 9: 522-536, 2013.
47. Jentsch TJ: Chloride and the endosomal-lysosomal pathway: Emerging roles of CLC chloride transporters. J Physiol 578: 633-640, 2007.

48. Zhang B, Zhang J, Huang HZ, Xu ZY and Xie HL: Expression and role of metalloproteinase- 2 and endogenous tissue regulator in ameloblastoma. J Oral Pathol Med 39: 219-222, 2010. 